Article

\title{
Optimal Decisions and Coordination in a Socially Responsible Supply Chain with Irresponsibility Risk
}

\author{
Qian Wang ${ }^{1}$, Yongguang Zhong ${ }^{1}$ and Guangye $\mathrm{Xu}^{2, *}$ \\ 1 Business School, Qingdao University, Qingdao 266071, China; qianwang1025@163.com (Q.W.); \\ zhongyongguang@qdu.edu.cn (Y.Z.) \\ 2 School of Management, Nanjing University of Posts and Telecommunications, Nanjing 210003, China \\ * Correspondence: guangyexu@yeah.net
}

Received: 25 September 2019; Accepted: 7 December 2019; Published: 17 December 2019

\begin{abstract}
Many companies make some stakeholders pleased but others cannot. To help understand why, it is very important to study the coexistence of corporate social responsibility (CSR) and corporate social irresponsibility (CSI). This paper considers a manufacturer with irresponsibility risk in a centralized and decentralized socially responsible supply chain, and uses a Stackelberg game to investigate the optimal policies on price and CSR investment level. This paper also examines the influence of consumer responsibility awareness and CSR investment efficiency on the decision behaviors of the manufacturer and retailer. Moreover, we developed a new mechanism to coordinate the decentralized supply chain system, which consists of the retailer participating in CSR and revenue sharing. Our results indicate that the manufacturer's and retailer's optimal decisions may not be significantly influenced by consumer responsibility awareness, but the effect of CSR investment efficiency is significant. Our results also show that if the degree of retailer participation and the proportion of revenue sharing are of moderate size, then not only can the contract mechanism coordinate the decentralized socially responsible supply chain, but it can ensure that a win-win situation can be achieved by the supply chain members.
\end{abstract}

Keywords: socially responsible supply chain; corporate social responsibility; corporate social irresponsibility; irresponsibility risk; coordination mechanism

\section{Introduction}

As corporations face pressure from different internal and external stakeholders (such as consumers, employees, investors, communities, and so on), firms have begun to integrate corporate social responsibility (CSR) into business operations to positively impact the stakeholders [1]. CSR has been disclosed widely by companies publishing CSR reports regularly around the world [2]. Correspondingly, many authors in related academic researches have been explored the significance of many CSR activities, including better reputation [3,4] stronger financial performance [5,6] and so forth.

Some inappropriate social behaviors, known as corporate social irresponsibility (CSI), can be reduced or mitigated by CSR, but the risk of irresponsible actions taken by firms still exists $[7,8]$. That is to say, CSR coexists with CSI, and there is a focus on resources and attention to assist the improvement of corporate social performance [9-11]. However, it is not always easy for firms to balance between promoting CSR and preventing CSI [12]; more specifically, a firm may have a good strategy on diversity and equality of opportunity, but it may be weak in its commitment to address environmental pollution. Given that the firm is satisfying some communities while ignoring others, exploring the ramifications of the coexistence of CSI and CSR is essential. Further, since the contradictory relationship between socially responsible promise and irresponsible behavior is a reality, there are plenty of problems available to study. 
The purpose of the paper is to deliver a deeper understanding of the coexistence of CSR and CSI through a game model in a supply chain system. Some researchers have merged social responsibility into supply chain, such as $[13,14]$. Although the literature increases every year, and there are many conceptual papers on socially responsible supply chains, the full extent of their positive capacity is still not well understood [15]. On the other side, these works of literature concentrate predominantly on the positive, that of CSR, while neglecting the negative side of CSI.

In order to address our objective, this paper considers a socially responsible supply chain including one retailer and one manufacturer with irresponsibility risk. In this example, the features of socially responsible and irresponsible behaviors are primarily owned by the manufacturer; meanwhile, the retailer ordered products prior to the CSI behaviors. We developed an optimal decision model in a centralized and decentralized socially responsible supply chain, exploring the impacts of consumer responsibility awareness and CSR investment efficiency on the pricing of the retailer and manufacturer and the CSR investment level of the manufacturer. By comparing the decentralized and centralized systems, we can provide a new contract that coordinates the decentralized socially responsible supply chain.

The rest of our paper is organized as follows: Section 2 reviews related literature. Section 3 describes problems and develops models of both a centralized and decentralized socially responsible supply chain. Section 4 designs a socially responsible supply chain coordination contract with irresponsibility risk. Some numerical experiments are given in Section 5, while Section 6 concludes the study and outlines directions for future research. Appendix A includes all proofs of this research.

\section{Literature Review}

Our models build relations between two lines of literature: CSR and CSI, and literature regarding the socially responsible supply chain. We discuss them respectively.

\subsection{Corporate Social Responsibility and Corporate Social Irresponsibility}

Relative to responsibility, irresponsibility is less expressly discussed in the CSR literature, and is often simply regarded as the inverse of CSR. As significant outcomes of CSI are uncovered, the scientific literature has begun to concentrate on the notion of CSI. The first academic research was Armstrong [16], who proposed that CSI was immoral decisions made by managers, and found that irresponsible decisions were rarely acceptable by groups of impartial observers. Lin-Hi and Müller [17] defined CSI as formed from "corporate parts that make for (feasible) defects and/or damage to other proportions, [with] intervention of law imagining as a competent, but not an important situation." To learn more about the concept of CSI please refer to [18]. However, in general, CSI is a broad and slippery concept. Some academics have proposed an active relationship between CSR and CSI. These scholars have faith that CSR serves as a tactic to counterbalance socially irresponsible behaviors. In this area, McMahon [19] demonstrated that CSI is the opposite of CSR by illustrating the Chrysler case; Kotchen and Moon [20] showed the points that enterprises accomplish socially responsible actions to offset company irresponsibility; and Kang et al. [9] also argued that corporations dedicate resources to CSR to offset their CSI. In accordance with this literature $[9,19,20]$, the concept of CSI in this paper is defined as the opposite of CSR. That is, low CSR investment level leads to high irresponsibility risk and high CSR investment level leads to low irresponsibility risk.

Meanwhile, CSR and CSI have been rarely studied to ascertain their impact on corporate performance. Price and Sun [21] explored the impacts of CSR and CSI on corporate performance using a moderating high-low matrix. They found that CSI events have longer abiding consequences than CSR enterprises, and those corporations engaged in both little CSR and little CSI perform better than companies taking part in high degrees of both. Lange and Washburn [22] also found that CSI may generate serious social issues compared with CSR. Kang et al. [9] showed that some companies invest in CSR not because they are doing well financially but because they believe that it is the "right" thing to do. However, other corporations participate in CSR in an effort to see significant financial 
returns. They also suggested that the repentance element is ineffective at offsetting passive influence impacts according to CSI. Recently, Chen et al. [10] showed U-shaped relationships between CSR and corporate financial performance, and found that cost leadership and differentiation strategies may actively center the connection between CSR and corporate financial performance, and passively center the correlation between CSI and corporate financial performance. Their study discovery purports to explicate why directors do not usually make socially responsible resolutions, but may think inevitable irresponsible decisions to improve company conditions. Walker et al. [11] examined CSR, CSI and their relationships with companies situated in a coordinated market economy and a free market economy. They believed that firms mirror their institutional situations, and that coordinated market economies systematically maintain larger CSR, lower CSI and financial wages matching the types of corporate behavior society wants. Salaiz et al. [12] demonstrated that CSR and CSI are both whole parts of the broader concept of corporate social performance, and provided some insight for directors making cardinal determinations on how to assign resources to CSR and CSI, and react to the desires of their shareowners and other shareholders. They suggested that the primal thing to better a company's situation may lie in maximizing CSR rather than in minimizing CSI.

Even though the primary sources of the above studies are questionnaires, case or empirical analysis, and information analysis, these researches offer a basis and foundation for model building and analyzing in this paper.

\subsection{Socially Responsible Supply Chain}

Socially responsible supply chains are conceptualized as a composite of internal organizational direction and external partnership for social issues in supply chains by Park-Poaps and Rees [23]. The supply chains can be assigned to a sustainable supply chain. Sustainable supply chains have been well studied. Since Seuring [24] and Brandenburg et al. [25] have detailed descriptions of this issue, we won't review more about it here. In recent years, socially responsible supply chains have been an active study direction with important effective significance $[15,26]$. Among the earliest works reported are Carter and Jennings [27], who incorporate the concept of social responsibility into supply chains. They showed that providers may be in a better rival position according to increased involvement by buying directors in socially responsible activities and improving the situation as estimated by prize and potency. Cruz $[28,29]$ discussed the influence of social responsibility on supply chain members with a multicultural decision-making method; Carter and Rogers [30] stressed that social issues should interfere with the operations management of supply chain members; Tate et al. [31] showed that improving CSR performance of a supply chain may affect consumer choice, corporate image and reputation; Boehe and Cruz [32] further suggested that if a firm wants to protect their corporate image and enhance corporate reputation, then the firm must ensure that social responsibility applies to their supply chain; Hoejmose et al. [33] explored that the impacts of social responsibility on supply chain, and found that low-cost manufacturers largely ignore social responsibility in supply chain management; and Basta et al. [34] reviewed and analyzed 590 articles on a socially responsible supply chain and provided a clear understanding of this subject.

Different from the above study, we focus on quantitative models of socially responsible supply chains. As primary works in this area, Guo et al. [35] built a responsible purchasing model. They found that because of responsible purchasing reducing the risk to a manufacturer, the manufacturer will still purchase from a responsible supplier even if the consumer's willingness to pay for responsibility is zero. Plambeck and Taylor [36] considered a socially responsible supply chain, in which an upstream firm chose CSR investment level and made an effort to avoid an audit downstream. They showed that CSR investment level is inadequate when government enforcement is weak or responsibility is costly. Chen et al. [37] developed a stylized socially responsible supply chain model with mutual commitments, and suggested that if reciprocal commitments are comparable, then a win-win situation can occur. Wu et al. [38] and Ma et al. [39] showed that contracts could reduce the potential for corporate misconduct and improve CSR investment level. Kraft et al. [40] discussed the impacts of supply chain visibility on 
CSR investment level, and their results indicated that higher visibility could help to reduce this tendency not to invest in CSR. In addition, Yang et al. [41] explored the influences on the optimal decisions of a socially responsible supply chain with green investment, and Liu et al. [13] developed a three-stage game model and explored the impacts of a government subsidy on CSR investment level, supply chain members and social welfare. Their results showed that the higher CSR investment level is, the more positive the effect on the supply chain. However, the literature only dealt with the pricing and CSR investment, and did not discuss the importance of the contract mechanism for coordinating the socially responsible supply chain.

Recently, and with growing concern, a string of scientific papers has highlighted issues with coordination of socially responsible supply chains. Ni et al. [42] argued for a wholesale price contract in a supply chain, where a supplier invests in CSR and a manufacturer shares the investment cost. Panda [43] considered two cases of socially responsible supply chains including a responsible retailer and responsible manufacturer, and discussed a revenue sharing contract to coordinate the two supply chain systems. Their results showed that revenue sharing contract can increase CSR investment levels and reduce channel conflict. Hsueh [44] designed a new revenue sharing contract to coordinate a supply chain with a responsible manufacturer, and showed that the new contract can achieve different levels of CSR. In addition, Zhao and Yin [45] and Raza [46] also considered a revenue sharing contract and discussed socially responsible supply chain coordination when the demand is stochastic. Modak et al. [47] studied coordination mechanisms for a socially responsible supply chain with competing retailers. They found that if the franchise fee satisfies some conditions, then a two-part tariff contract can mitigate channel conflict and can achieve a win-win situation. Panda et al. [48] and Modak et al. [49] explored coordination in a three-layer supply chain with CSR investment. Panda and Modak [50] discussed how to coordinate a supply chain when the players maximize social welfare, and found that strategic bargaining is used for coordinating the supply chain, and that the social welfare-maximizing player may get a higher profit than the profit-maximizer. Jokar et al. [14] discussed CSR issues in a supply chain under two situations: where the manufacturer has a social responsibility and the retailer has a social responsibility. They proposed a combined contract to coordinate the supply chain, and also showed that the Nash bargaining model could offer a win-win situation for supply chain members in each case. However, all the papers above were conducted absent an understanding of irresponsibility risk (i.e., they did not involve CSR and CSI simultaneously). Our study is different from previous literature and we consider that a manufacturer has irresponsibility risk in a socially responsible supply chain.

The aim of this paper is to develop a modeling framework for decisions of pricing and CSR investment in a social responsibility supply chain with irresponsibility risk. We compare a decentralized system with a centralized system, then design a contract to coordinate the socially responsible supply chain. Our contributions can be summarized as follows: (1) We develop a Stackelberg game model that considers both CSR and CSI. (2) We explore the impacts of consumer responsibility awareness and CSR investment efficiency on the optimal policies of the manufacturer and retailer. (3) We design a new contract to coordinate the socially responsible supply chain with irresponsibility risk, and the contract can ensure that a win-win situation may be achieved.

\section{Model Development}

Consider a socially responsible supply chain, including a retailer and a manufacturer. The manufacturer produces a single product at a unit cost $c$ and sells his product to the retailer at wholesale price $w$. The retailer sells the product to customers at a price $p$. The economic value of the product to consumers is $v$, and consumers are heterogeneous in the economic value, which is uniformly distributed in the interval $[0, a]$. The manufacturer invests in CSR, which make an investment level $s(0<s<1)$. Similar to Raza [45], CSR investment level is defined as the level or degree to which a company can engage in socially responsible activities. Furthermore, following Wu et al. [38], Ma et al. [39] and Raza [46], the investment costs of CSR have a nonlinear increase in $s$, and the costs can be assumed to be $k s^{2} / 2$, where $k$ is CSR investment parameter. When $k$ is smaller, CSR investment represents more efficiency. While the manufacturer can 
reduce or mitigate CSI by investing in CSR, CSI may be inevitable when CSR investment level is not particularly high. In other words, CSR and CSI may coexist and the manufacturer has an irresponsibility risk. Following McMahon [19], Kotchen and Moon [20] and Kang et al. [9], the irresponsibility risk is supposed to be $1-s$, and if CSI occurs, then customers will not buy the product. More specifically, a consumer considers purchasing a surplus of $U=v-p+\lambda s$ when CSI does not occur. The parameter $\lambda$ is CSR investment level sensitivities for customers and it represents consumer responsibility awareness in this paper. However, if CSI occurs, then the consumer's utility function is zero.

Due to the orders taking place before consumer purchasing, the order quantities of the retailer are $d=a-p+\lambda s$ when $v \sim \mathrm{U}[0, a]$. If the probability of CSI not occurring is $s$, then the actual sales of the retailer are $s d$. Without loss of generality, we take into considerations the following assumptions:

(1) The manufacturer and retailer have the same and full information on each supply chain member's demand, cost, and decision rules, and they are risk neutral and always make rational decisions.

(2) The manufacturer is a leader and first determines the CSR investment level and wholesale price, while the retailer is a follower and determines the retail price according to the manufacturer's decision.

(3) The unit cost of the product $c=0$.

(4) To avoid $s=1$, the CSR investment parameter is $k>k_{0}$, where $k_{0}=(a+\lambda)(a+3 \lambda) / 4$.

(5) The superscript " $C$ ", " $D$ " and " $M$ " mean the parameters corresponding to the centralized, decentralized and coordination mechanism situations, respectively, and the subscript " $m$ " and " $r$ " mean the parameters corresponding to the manufacturer and retailer.

The first subsection considers a centralized socially responsible supply chain in which both the manufacturer and retailer are centralized to maximize the profit of the supply chain system; that is, the manufacturer is vertically integrated with the retailer in this case, and makes decisions regarding CSR investment level and retail price.

The second subsection considers a decentralized socially responsible supply chain without coordinating contracts when the manufacturer is a leader. In this decentralized case, both the manufacturer and retailer make their own decisions to maximize their individual profit. The decision rules are assumed to follow this sequence: The manufacturer first determines CSR investment level and then sets wholesale price. Thereafter, the retailer sets their retail price based on the manufacturer's decisions.

\subsection{Centralized Socially Responsible Supply Chain System}

The wholesale price is no longer a decision variable in a centralized socially responsible supply chain. The decision variables are only CSR investment level and retail price, and the expected profit of the centralized socially responsible supply chain is

$$
\pi^{C}=p s(a-p+\lambda s)-\frac{k s^{2}}{2}
$$

Proposition 1. The $\pi^{C}$ is a concave in $p$, but not jointly concave in $p$ and s.

Proposition 1 shows that the optimal solutions of $p$ and $s$ cannot be solved by using the first-order conditions, but we find that $\pi^{C}$ has a unique optimal value for any given $s \in(0,1)$. Using the two-stage optimization technique, we get the equilibrium of the centralized model. Hence, we first present the best response to retail price on CSR investment level (see Proposition 2), and then deduce the optimal CSR investment level to maximize $\pi^{C}$ (see Proposition 3).

Proposition 2. For any given $s \in(0,1)$, the best response to the retail price is given by

$$
p^{C}(s)=\frac{a+\lambda s}{2}
$$


Proposition 2 shows that the best response to retail price increases by decreasing the irresponsibility risk in the centralized system. This conclusion obtained is explicit because the lower irresponsibility risk means more will have to be done for the money, and the retail price increase should have been higher. In addition, the rate of change of the best response to retail price decreases with respect to the irresponsibility risk is affected by consumer responsibility awareness, and the impact of the irresponsibility risk on the retail price is strong when consumer responsibility awareness is high.

Proposition 3. In a centralized socially responsible supply chain, the optimal solutions and expected profit are as follows:

$$
\begin{gathered}
s^{C *}=\frac{2 k-2 \lambda a-A_{1}}{3 \lambda^{2}} \\
p^{C *}=\frac{2 k+\lambda a-A_{1}}{6 \lambda} \\
\pi^{C *}=\frac{\left.(2 k-2 \lambda a)-A_{1}\right)\left(\left(k-\lambda a+A_{1}\right)^{2}-9 k(k-2 \lambda a)\right)}{2}
\end{gathered}
$$

where $A_{1}=\sqrt{(2 k-\lambda a)^{2}-4 k \lambda a}$.

\subsection{Decentralized Socially Responsible Supply Chain System}

In a decentralized socially responsible supply chain without coordinating contracts, both the manufacturer and retailer desire to maximize their expected profit as a goal. The expected profit of the retailer is

$$
\pi_{r}^{D}=p s(a-p+\lambda s)-w(a-p+\lambda s)
$$

and the expected profit of the manufacturer is

$$
\pi_{m}^{D}=w(a-p+\lambda s)-\frac{k s^{2}}{2}
$$

Using the two-stage optimization technique, we first give and analyze the best response functions of pricing on the irresponsibility risk in Proposition 4, then present the game equilibrium in Proposition 5.

Proposition 4. For any given s, the best response functions of the manufacturer and retailer are as follows:

$$
\begin{aligned}
& w^{D}(s)=\frac{(a+\lambda s) s}{2} \\
& p^{D}(s)=\frac{3(a+\lambda s)}{4}
\end{aligned}
$$

To analyze the impacts of the irresponsibility risk on the best pricing policies of the manufacturer and retailer, we deduce Corollary 1 by Proposition 4 .

Corollary 1. (i) If $s \geq \frac{3}{4}$ or $s<\frac{3}{4}$ and $\lambda<\frac{2 a}{3-4 s}$, then $\frac{d w^{D}(s)}{d s}>\frac{d p^{D}(s)}{d s}>0$; (ii) If $s<\frac{3}{4}$ and $\lambda>\frac{2 a}{3-4 s^{\prime}}$, then $\frac{d p^{D}(s)}{d s}>\frac{d w^{D}(s)}{d s}>0$.

Corollary 1 indicates that wholesale price and retail price increase with CSR investment level in the decentralized system, and it is reasonable. The change rate of wholesale price relative to CSR investment level is larger than that of retail price when the irresponsibility risk is low or the irresponsibility risk is high and consumer responsibility awareness is low. However, when the irresponsibility risk and 
consumer responsibility awareness are high, the change rate of retail price relative to CSR investment level is larger than that of wholesale price.

Proposition 5. In a decentralized socially responsible supply chain, the optimal solutions and expected profit are as follows:

$$
\begin{gathered}
s^{D *}=\frac{4 k-2 \lambda a-A_{2}}{3 \lambda^{2}} \\
w^{D *}=\frac{\left(4 k-2 \lambda a-A_{2}\right)\left(4 k+\lambda a-A_{2}\right)}{18 \lambda^{3}} \\
p^{D *}=\frac{4 k+\lambda a-A_{2}}{4 \lambda} \\
\pi_{r}^{D *}=\frac{\left(4 k-2 \lambda a-A_{2}\right)\left(4 k+\lambda a-A_{2}\right)^{2}}{432 \lambda^{4}} \\
\pi_{m}^{D *}=\frac{\left(4 k-2 \lambda a-A_{2}\right)\left(\left(2 k-\lambda a+A_{2}\right)^{2}-36 k(k-\lambda a)\right)}{216 \lambda^{4}}
\end{gathered}
$$

where $A_{2}=\sqrt{(4 k-\lambda a)^{2}-8 k \lambda a}$.

We have Corollary 2 by Proposition 3 and Proposition 5.

Corollary 2. (i) $s^{C *}>s^{D *}$; (ii) $\pi^{C *}>\pi_{r}^{D *}+\pi_{m}^{D *}$.

Corollary 2 demonstrates that the decentralized system will generate a high irresponsibility risk in comparison with the centralized system. Corollary 2 also shows that the decentralized system will reduce supply chain performance. These results can be attributed to double marginalization.

However, an interesting question needs to be answered. Can the incentives for the manufacturer and retailer be aligned through a coordination mechanism so that both of them are willing to make their decisions equal to the optimal decisions that will maximize the whole supply chain? We deal with this issue in the next section.

\section{Coordination Mechanism}

In this section, we provide a new combined contract mechanism, which consists of the retailer participating in CSR and revenue sharing contract, and we called an RP-RS contract. On the one hand, to reduce irresponsibility risk, the retailer may participate in the manufacturer's CSR planning, and the degree of participation is $\eta(0<\eta<1)$. On the other hand, the manufacturer may offer a lower wholesale price to the retailer, and the retailer shares their revenue with the manufacturer, and the proportion of revenue sharing is $\phi(0<\phi<1)$.

Under the RP-RS contract, we can determine the retailer's and the manufacturer's expected profit as follows:

$$
\begin{aligned}
& \pi_{r}^{M}=(1-\phi) p s(a-p+\lambda s)-w(a-p+\lambda s)-\frac{\eta k s^{2}}{2} \\
& \pi_{m}^{M}=w(a-p+\lambda s)+\phi p s(a-p+\lambda s)-\frac{(1-\eta) k s^{2}}{2}
\end{aligned}
$$

Proposition 6. If the contract parameters $(\eta, w, \phi)$ satisfy $\eta=1-\phi$ and $w=0$, then the contract can coordinate the decentralized socially responsible supply chain.

Proposition 6 demonstrates that the RP-RS contract can coordinate the decentralized socially responsible supply chain when the contract parameters are appropriate. Proposition 6 also indicates that the degree of participation of CSR interacts with the proportion of revenue sharing, and there 
is equality between them under the coordination status. In addition, the revenue sharing contract is consistent with existing research such as Cachon and Lariviere [51].

Even if the decentralized socially responsible supply chain can be coordinated under the RP-RS contract mechanism, it is not clear this contract mechanism will hold. Achieving a win-win strategy for supply chain players is becoming a very important subject in supply chain management. Hence, we will discuss the conditions of win-win under the coordination setting in the following corollaries.

Corollary 3. If the socially responsible supply chain can be coordinated under the RP-RS contract mechanism, then the optimal expected profit of the retailer and the manufacturer are as follows:

$$
\begin{gathered}
\pi_{r}^{M *}=(1-\phi) \pi^{C *} \\
\pi_{m}^{M *}=\phi \pi^{C *}
\end{gathered}
$$

or

$$
\begin{gathered}
\pi_{r}^{M *}=\eta \pi^{C *} \\
\pi_{m}^{M *}=(1-\eta) \pi^{C *}
\end{gathered}
$$

Corollary 3 shows that the RP-RS contract can not only coordinate a socially responsible supply chain but also allocate the total expected profit for the supply chain players arbitrarily. Therefore, the contract mechanism creates a win-win for the supply chain players. Under the socially responsible supply chain coordination, Corollary 3 also shows that the retailer's expected profit decreases and the manufacturer's expected profit increases with the proportion of revenue sharing, while the retailer's expected profit increases and the manufacturer's expected profit decreases with the degree of participation of CSR. In other words, the retailer should prefer to participate in CSR rather than share revenue, and the manufacturer should prefer to share the retailer's revenue rather than let them participate in CSR activities.

Corollary 4. Given $\eta=1-\phi$ and $w=0$, if $\phi \in\left[\frac{\pi_{m}^{D^{*}}}{\pi^{\mathrm{C}^{*}}}, 1-\frac{\pi_{r}^{D^{*}}}{\pi^{\mathrm{C}}}\right]$, then the RP-RS contract mechanism can achieve a win-win between the retailer and manufacturer.

Corollary 5. Given $\phi=1-\eta$ and $w=0$, if $\eta \in\left[\frac{\pi_{r}^{D^{*}}}{\pi^{C_{*}}}, 1-\frac{\pi_{m}^{D^{*}}}{\pi^{\mathrm{C}^{*}}}\right]$, then the RP-RS contract mechanism can achieve a win-win between the retailer and manufacturer.

Corollary 4 and Corollary 5 indicate that if the RP-RS contract mechanism exists for a reasonable length interval, it is a win-win in the socially responsible supply chain.

\section{Numerical Analysis}

We illustrate our theoretical results by using some numerical examples and discuss some related issues in a socially responsible supply chain with irresponsibility risk. Let $a=10, k=100$ and $\lambda \in[1,5]$ or $\lambda=3$ and $k \in[80,150]$.

\subsection{Comparative Analysis for Centralized and Decentralized Supply Chains}

In this subsection, we focus on the impacts of consumer responsibility awareness and CSR investment efficiency on optimal decisions and expected profit, as summarized in Figures 1-4. 


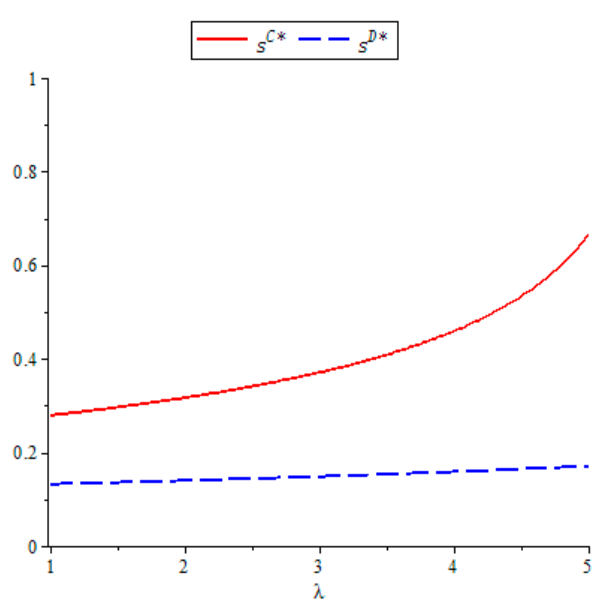

(a)

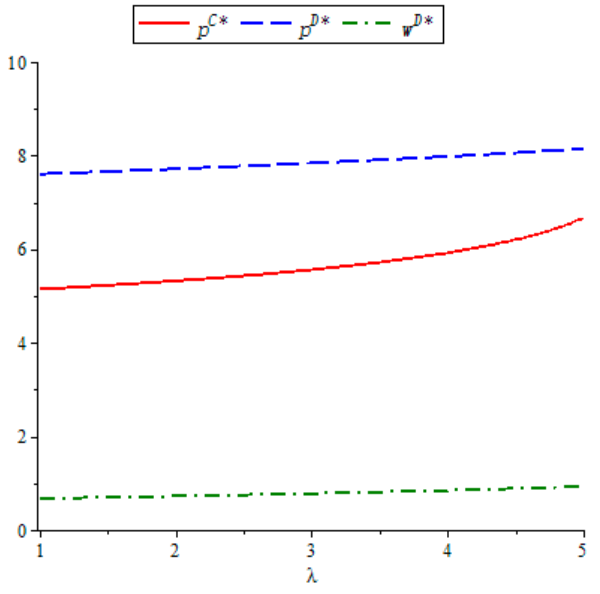

(b)

Figure 1. (a) Impacts of $\lambda$ on corporate social responsibility (CSR) investment level when $k=100$; (b) impacts of $\lambda$ on prices when $k=100$.

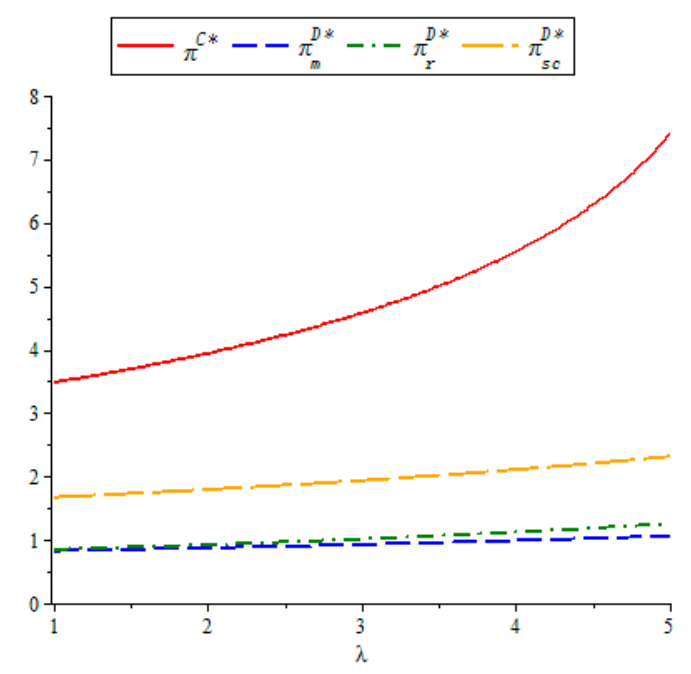

Figure 2. Impacts of $\lambda$ on expected profit when $k=100$.

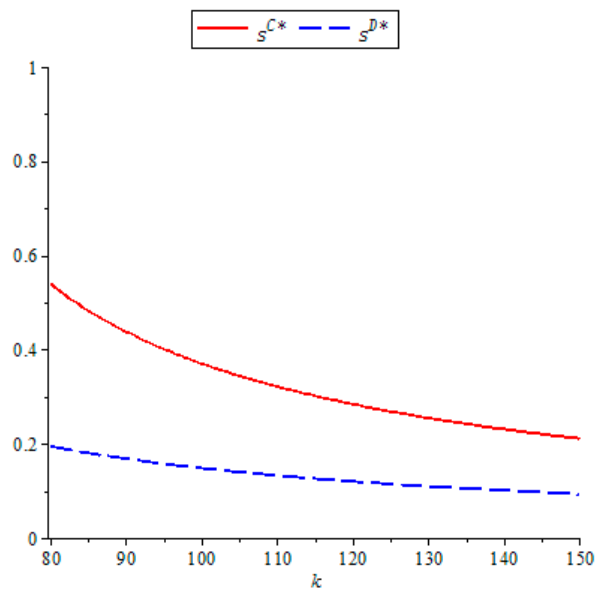

(a)

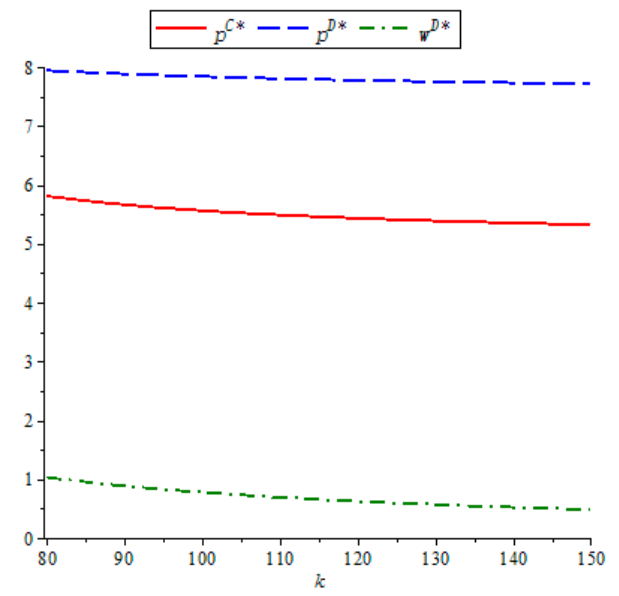

(b)

Figure 3. (a) Impacts of $k$ on CSR investment level when $\lambda=3$; (b) Impacts of $k$ on prices when $\lambda=3$. 


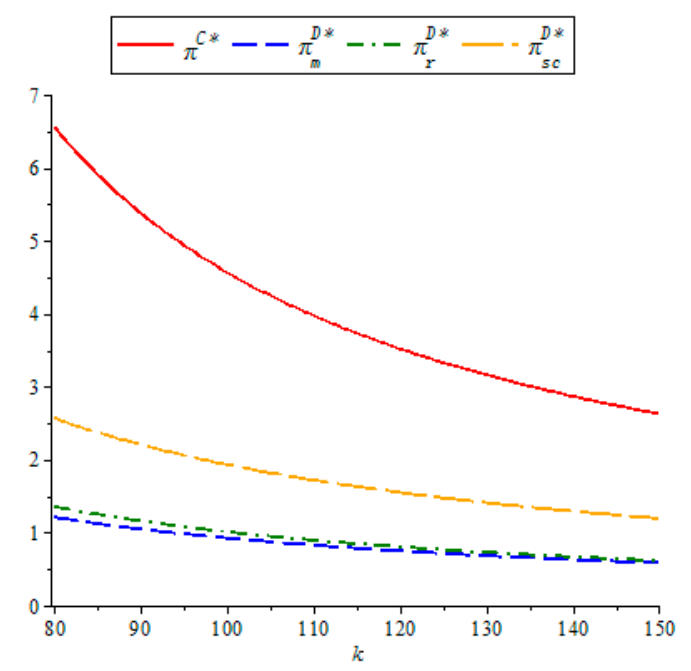

Figure 4. Impacts of $k$ on expected profit when $\lambda=3$.

As shown in Figures 1 and 2, when CSR investment efficiency is fixed, the optimal decisions and expected profit increase with consumer responsibility awareness in both the centralized and decentralized systems. However, we can also see that if consumer responsibility awareness is high, the optimal decisions and expected profit in the centralized situation give a more obvious effect than those in the decentralized situation. Figures 1 and 2 indicate that consumer responsibility awareness cannot significantly influence the manufacturer and retailer in a decentralized system, and this may be a main reason that the manufacturer is not actively investing in CSR. Hence, even if consumer responsibility awareness is high, the decentralized system may have a high irresponsibility risk (such as $1-s>0.8$ ). Furthermore, Figures 1 and 2 also show that the optimal CSR investment level and expected profit in the centralized system have more than twice those in the decentralized setting, and the importance of socially responsible supply chain coordination is evident.

As shown in Figures 3 and 4, when consumer responsibility awareness is fixed, the optimal decisions and expected profit increase with CSR investment efficiency in both the centralized and decentralized systems. Different from previous illustrated example, there is not an obvious difference in the two systems, and the reason is that the manufacturer is motivated to invest in CSR. We also find that if CSR investment efficiency is low, then the centralized and decentralized systems have a high irresponsibility risk, which means that the manufacturer and retailer must do everything they ought to improve CSR investment efficiency.

\subsection{Impacts of Coordination Mechanism}

In this subsection, when $k=100$ and $\lambda=3$, we obtain $\pi_{m}^{D *}=0.9227, \pi_{r}^{D *}=1.0084$ and $\pi^{C *}=4.5725$. We focus on the impacts of the RP-RS contract mechanism on the retailer's and manufacturer's expected profit when $\eta=1-\phi$ and $w=0$. Furthermore, we assume that $\Delta \pi_{m}=\pi_{m}^{M *}-\pi_{m}^{D *}$ and $\Delta \pi_{r}=\pi_{r}^{M *}-\pi_{r}^{D *}$, as summarized in Figures 5 and 6.

Figure 5 shows that the manufacturer's expected profit increases with the proportion of the revenue generated by the retailer, and this is explained by Corollary 3 . Figure 5 also shows that if $\phi \in[0.2018,0.7795]$, then the RP-RS contract can achieve a win-win situation, and it signifies that the contract is a valid mechanism for supply chain players. Similarly, in Figure 6, we can see that the retailer's expected profit increases and the manufacturer's expected profit decreases with the degree of participation in CSR. Hence, Figure 6 suggests that the retailer should actively participate in CSR with the manufacturer under the RP-RS contract. We can also see that if $\eta \in[0.2205,0.7982]$, then the RP-RS contract can achieve a win-win situation, signifying that the contract is a valid mechanism. 


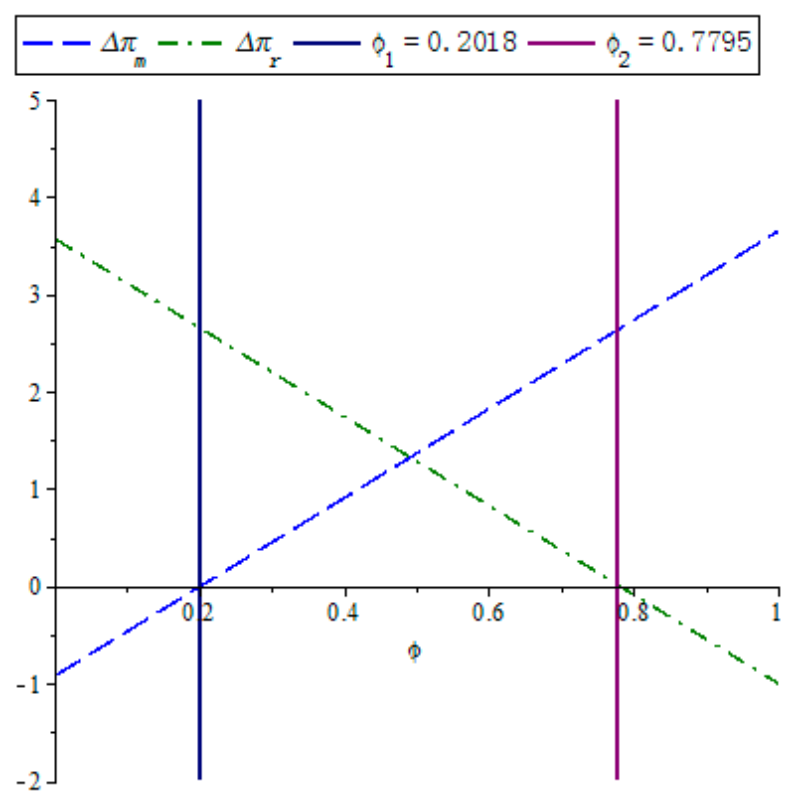

Figure 5. Impacts of $\phi$ on expected profit.

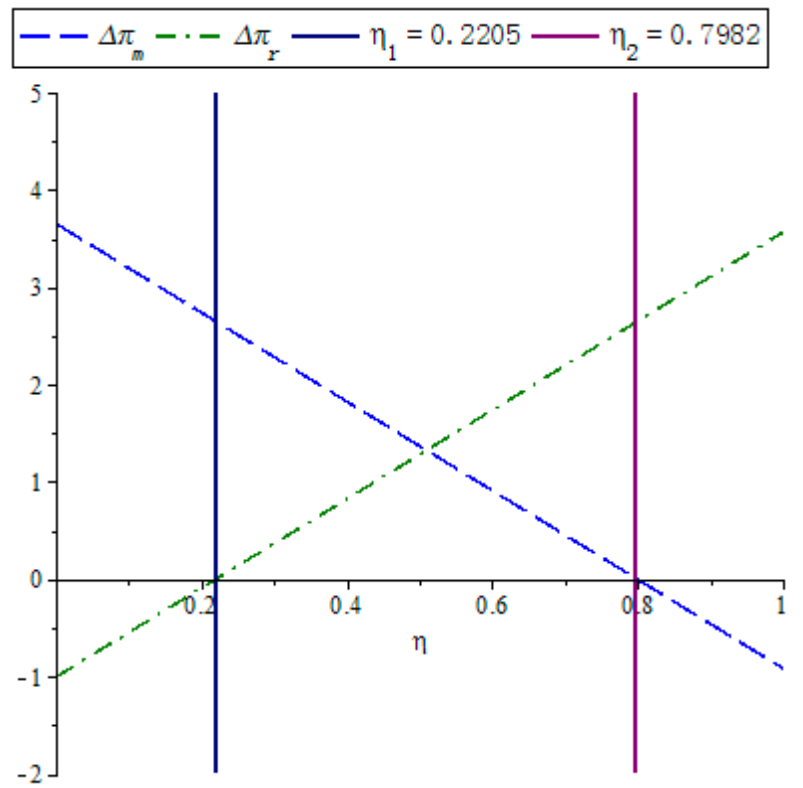

Figure 6. Impacts of $\eta$ on expected profit.

\section{Conclusions}

We have developed a model to discuss the important influence of irresponsibility risk in a socially responsible supply chain. We examined the optimal decisions for prices and CSR investment level in a centralized and decentralized system based on a Stackelberg game. We analyzed the impacts of consumer responsibility awareness and CSR investment efficiency on the optimal decisions and expected profit of the supply chain members. To coordinate the socially responsible supply chain, we designed a new coordination mechanism, called the RP-RS contract.

Our results showed that irresponsibility risk strongly influences the pricing decision of the manufacturer and retailer. Regardless of whether a centralized or decentralized system is used, the price will decrease with the irresponsibility risk. The centralized system can acquire low irresponsibility risk and high supply chain performance in comparison with the decentralized system. Moreover, we found that the optimal decisions and expected profit increase with consumer responsibility awareness and CSR 
investment efficiency. We also found that CSR investment efficiency is more important than consumer responsibility awareness for the supply chain members. Compared to the decentralized system without contract mechanism, we showed that the RP-RS contract can coordinate the decentralized socially responsible supply chain when the degree of participation of CSR plus the proportion of revenue sharing is equal to one and the wholesale price equals the unit product cost. Finally, by analyzing the impacts of the RP-RS contract mechanism on the retailer's and manufacturer's expected profit, we deduced some conditions in which the RP-RS contract can be implemented. Our results also showed that the supply chain members have a win-win as long as the degree of retailer participation or the proportion of revenue sharing is neither high nor low.

Our study also has some limitations. We assumed all information is known, such as consumer responsibility awareness and CSR investment efficiency. However, the information known may be asymmetric. Moreover, it may be useful to develop an equilibrium model in the presence of multiple manufacturers.

Author Contributions: Q.W. raised the research question and wrote the manuscript. Y.Z. supervised the research work and provided constructive suggestions to improve this paper. G.X. made some theoretical derivations and numerical analyses.

Funding: This work is supported by National Natural Science Foundation of China (No. 71573144, 71401143).

Acknowledgments: The authors especially thank the editors and anonymous reviewers for their kindly review and helpful comments.

Conflicts of Interest: The authors declare no conflict of interest.

\section{Appendix A}

Proof of Proposition 1. Using the second-order partial derivatives of (1) with $p$, we have $\partial^{2} \pi^{C} / \partial p^{2}=$ $-2 s<0$, so $\pi^{C}$ is a concave in $p$.

Due to $\partial^{2} \pi^{C} / \partial s^{2}=2 \lambda p-k$, this equation may be positive for large enough $p$, so $\pi^{C}$ is not jointly concave in $p$ and $s$.

Proof of Proposition 2. Due to $\partial \pi^{C} / \partial p=(a-2 p+\lambda s) s$, we get $p^{C}(s)=\frac{a+\lambda s}{2}$ by the first-order conditions.

Proof of Proposition 3. By substituting (2) into (1), we get:

$$
\pi^{C}(s)=\frac{(a+\lambda s)^{2} s}{4}-\frac{k s^{2}}{2}
$$

We can also get $\frac{d \pi^{c}(s)}{d s}=\frac{3 \lambda^{2} s^{2}}{4}-(k-\lambda a) s+\frac{a^{2}}{4}$ and $\frac{d^{2} \pi^{c}(s)}{d s^{2}}=\frac{3 \lambda^{2} s}{2}-(k-\lambda a)$. Due to $k>k_{0}$, we have $\lim _{s \rightarrow 0} \frac{d \pi^{C}(s)}{d s}=\frac{a^{2}}{4}>0$ and $\lim _{s \rightarrow 1} \frac{d \pi^{C}(s)}{d s}=-\left(k-k_{0}\right)<0$, so it can be easily proved that (3) is a root of $\frac{d \pi^{C}(s)}{d s}$ in $s \in(0,1)$. Substituting (3) into $\frac{d^{2} \pi^{C}(s)}{d s^{2}}$, we have $\frac{d^{2} \pi^{C}(s)}{d s^{2}}=-\frac{A_{1}}{2}<0$, that is, $\pi^{C}(s)$ is a concave in $s \in(0,1)$. Thus, (3) is a unique optimal solution of the centralized case.

Substituting (3) into (2) and (A1), we get (4) and (5).

Proof of Proposition 4. Obviously, $\pi_{r}^{D}$ is a quadratic concave function of $p$. Taking the first-order conditions, we get

$$
p^{D}(w, s)=\frac{\lambda s^{2}+a s+w}{2 s}
$$

Substituting (A2) into (7) and simplifying, we have

$$
\pi_{m}^{D}(w, s)=\frac{-w^{2}+(a+\lambda s) s w-k s^{3}}{2 s}
$$


It can be easily proved that $\pi_{m}^{D}(w, s)$ is a quadratic concave function of $w$, but $\pi_{m}^{D}(w, s)$ is not jointly concave in $w$ and $s$. Thus, we get (8) by using the first-order conditions. Substituting (8) into (A2), we get (9).

Proof of Corollary 1. We get $\frac{d w^{D}(s)}{d s}=\frac{a+2 \lambda s}{2}>0$ and $\frac{d p^{D}(s)}{d s}=\frac{3 \lambda}{4}>0$ from Proposition 4 , then $\frac{d w^{D}(s)}{d s}-$ $\frac{d p^{D}(s)}{d s}=\frac{2 a+4 \lambda s-3 \lambda}{4}$ can be easily proved.

Proof of Proposition 5. By substituting (8) into (A3) we get:

$$
\pi_{m}^{D}(s)=\frac{(a+\lambda s)^{2} s}{8}-\frac{1}{2} k s^{2}
$$

It can be easily proven that $\pi_{m}^{D}(s)$ is a quadratic concave in $s \in(0,1)$ when $k>k_{0}$. Further, we get that (10).

Substituting (10) into (8) and (9), we get (11) and (12), then we have (13) and (14).

Proof of Corollary 2. (i) We have $s^{C *}-s^{D *}=\frac{A_{2}-\left(2 k+A_{1}\right)}{3 \lambda^{2}}$ from (3) and (10). From this it can be easily obtained that $A_{2}^{2}-\left(2 k+A_{1}\right)^{2}=4 k\left(2 k-2 \lambda a-A_{1}\right)>0$, so $s^{C *}>s^{D *}$.

(ii) From (A1) and Proposition 3, we have $\pi^{C *}>\pi^{C}\left(s^{D^{*}}\right)=\frac{\left(a+\lambda s^{D^{*}}\right)^{2} s^{D^{*}}}{4}-\frac{k\left(s^{D^{*}}\right)^{2}}{2}$. From this it can be easily obtained that $\pi^{C}\left(s^{D^{*}}\right)-\left(\pi_{r}^{D *}+\pi_{m}^{D *}\right)=\frac{\left(a+\lambda s^{D^{*}}\right)^{2} s^{D *}}{16}>0$ by (13) and (14), so $\pi^{C *}>\pi_{r}^{D *}+\pi_{m}^{D *}$.

Proof of Proposition 6. Due to $\partial^{2} \pi_{r}^{M} / \partial p^{2}=-2(1-\phi) s<0, \pi_{r}^{M}$ is a quadratic concave function of $p$. Taking the first-order conditions, we get

$$
p^{M}(s)=\frac{(1-\phi)\left(\lambda s^{2}+a s\right)+w}{2(1-\phi) s}
$$

When the RP-RS contract can coordinate the supply chain, we have $p^{M}(s)=p^{C}(s)$, and solve the equation to gain $w=0$. Substituting $w=0$ and (A5) into (16), we get

$$
\pi_{m}^{M}(s)=\frac{\phi(a+\lambda s)^{2} s-2(1-\eta) k s^{2}}{4}
$$

It can be easily proven that $\pi_{m}^{M}(s)$ is a quadratic concave in $s \in(0,1)$ when $k>k_{0}$. Further, we get:

$$
s^{M *}=\frac{2((1-\eta) k-\phi \lambda a)-B_{1}}{3 \phi \lambda^{2}}
$$

where $B_{1}=\sqrt{4(1-\eta)^{2} k^{2}-8 \phi(1-\eta) \lambda a k+\phi \lambda^{2} a^{2}}$.

Solving the equation of $s^{M *}=s^{C *}$, we get that $\eta=1-\phi$.

Proof of Corollary 3. Substituting (3) and (4) into (15) and (16), we get (17) and (18) when $w=0$ and $\eta=1-\phi$. Further, we get (19) and (20) when $w=0$ and $\phi=1-\eta$.

Proof of Corollary 4. Comparing (13) with (17), we get $\phi \leq 1-\frac{\pi_{r}^{D *}}{\pi^{C *}}$ when $\pi_{r}^{M *} \geq \pi_{r}^{D^{*}}$. Besides, comparing (14) with (18), we get $\phi \geq \frac{\pi_{m}^{D_{*}^{*}}}{\pi^{C^{*}}}$ when $\pi_{m}^{M^{*}} \geq \pi_{m}^{D^{*}}$. From Corollary 2 (ii), we have $\left(1-\frac{\pi_{r}^{D^{*}}}{\pi^{C^{*}}}\right)-\frac{\pi_{m}^{D_{*}^{*}}}{\pi^{C^{* *}}}=$ $\frac{\pi^{\mathrm{C} *}-\left(\pi_{r}^{D^{*}}+\pi_{m}^{D^{*}}\right)}{\pi^{\mathrm{C*}}}>0$

Proof of Corollary 5. This Corollary is easily proved, so we omit it. 


\section{References}

1. Sodhi, M.S. Conceptualizing social responsibility in operations via stakeholder resource-based view. Prod. Oper. Manag. 2015, 24, 1375-1389. [CrossRef]

2. Cao, J.; Liang, H.; Zhan, X. Peer effects of corporate social responsibility. Manag. Sci. 2019. [CrossRef]

3. Graafland, J. Does corporate social responsibility put reputation at risk by inviting activist targeting? An empirical test among European SMEs. Corp. Soc. Resp. Env. 2018, 25, 1-13. [CrossRef]

4. Kim, S. The process model of corporate social responsibility (CSR) communication: CSR communication and its relationship with consumers' CSR knowledge, trust, and corporate reputation perception. J. Bus. Ethics. 2019, 154, 1143-1159. [CrossRef]

5. Wang, H.; Qian, C. Corporate Philanthropy and Corporate Financial Performance: The Roles of Stakeholder Response and Political Sccess. Acad. Manag. J. 2011, 54, 1159-1181. [CrossRef]

6. Lu, W.; Ye, M.; Chau, K.W.; Flanagan, R. The paradoxical nexus between corporate social responsibility and sustainable financial performance: Evidence from the international construction business. Corp. Soc. Resp. Env. 2018, 25, 844-852. [CrossRef]

7. Oikonomou, I.; Brooks, C.; Pavelin, S. The impact of corporate social performance on financial risk and utility: A longitudinal analysis. Financ. Manag. 2012, 41, 483-515. [CrossRef]

8. Mishra, S.; Modi, S. Positive and negative corporate social responsibility, financial leverage, and idiosyncratic risk. J. Bus. Ethics. 2013, 117, 431-448. [CrossRef]

9. Kang, C.; Germann, F.; Grewal, R. Washing away your sins? Corporate social responsibility, corporate social irresponsibility, and firm performance. J. Marketing. 2016, 80, 59-79. [CrossRef]

10. Chen, C.J.; Guo, R.S.; Hsiao, Y.C.; Chen, K.L. How business strategy in non-financial firms moderates the curvilinear effects of corporate social responsibility and irresponsibility on corporate financial performance. J. Bus. Res. 2018, 92, 154-167. [CrossRef]

11. Walker, K.; Zhang, Z.; Ni, N. The Mirror effect: Corporate social responsibility, corporate social irresponsibility and firm performance in coordinated market economies and Liberal market economies. Brit. J. Manag. 2019, 30, 151-168. [CrossRef]

12. Salaiz, A.; Evans, K.; Pathak, S.; Vera, D. The impact of corporate social responsibility and irresponsibility on firm performance: New insights to an old question. Organ. Dyn. 2019. [CrossRef]

13. Liu, Y.; Quan, B.T.; Xu, Q.; Forrest, J.Y.L. Corporate social responsibility and decision analysis in a supply chain through government subsidy. J. Clean. Prod. 2019, 208, 436-447. [CrossRef]

14. Jokar, A.; Hosseini-Motlagh, S.M. Simultaneous coordination of order quantity and corporate social responsibility in a two-echelon supply chain: A combined contract approach. J. Oper. Res. Soc. 2019, 1-16. [CrossRef]

15. Tang, C.S. Socially responsible supply chains in emerging markets: Some research opportunities. J. Oper. Manag. 2018, 57, 1-10. [CrossRef]

16. Armstrong, S.J. Social irresponsibility in management. J. Bus. Res. 1977, 5, 185-213. [CrossRef]

17. Lin-Hi, N.; Müller, K. The CSR bottom line: Preventing corporate social irresponsibility. J. Bus. Res. 2013, 66, 1928-1936. [CrossRef]

18. Riera, M.; Iborra, M. Corporate social irresponsibility: Review and conceptual boundaries. Eur. J. Manag. Econ. 2017, 26, 146-162. [CrossRef]

19. McMahon, T.F. From social irresponsibility to social responsiveness: The Chrysler/Kenosha plant closing. J. Bus. Ethics 1999, 20, 101-111. [CrossRef]

20. Kotchen, M.; Moon, J.J. Corporate social responsibility for irresponsibility. BE J. Econ. Anal. Policy $2012,12$. [CrossRef]

21. Price, J.M.; Sun, W. Doing good and doing bad: The impact of corporate social responsibility and irresponsibility on firm performance. J. Bus Res. 2017, 80, 82-97. [CrossRef]

22. Lange, D.; Washburn, N.T. Understanding attributions of corporate social irresponsibility. Acad. Manag. Rev. 2012, 37, 300-326. [CrossRef]

23. Park-Poaps, H.; Rees, K. Stakeholder forces of socially responsible supply chain management orientation. J. Bus. Ethics 2010, 92, 305-322. [CrossRef]

24. Seuring, S. A review of modeling approaches for sustainable supply chain management. Decis. Support Syst. 2014, 54, 1513-1520. [CrossRef] 
25. Brandenburg, M.; Govindan, K.; Sarkis, J.; Seuring, S. Quantitative models for sustainable supply chain management: Developments and directions. Eur. J. Oper. Res. 2014, 233, 299-312. [CrossRef]

26. Ahi, P.; Searcy, C. Measuring social issues in sustainable supply chains. Meas. Bus. Excell. 2015, 19, 33-45. [CrossRef]

27. Carter, C.R.; Jennings, M.M. Social responsibility and supply chain relationships. Transp. Res. E-Log. 2002, 38, 37-52. [CrossRef]

28. Cruz, J.M. Dynamics of supply chain networks with corporate social responsibility through integrated environmental decision-making. Eur. J. Oper. Res. 2008, 184, 1005-1031. [CrossRef]

29. Cruz, J.M. The impact of corporate social responsibility in supply chain management: Multicriteria decision-making approach. Decis. Support. Syst. 2009, 48, 224-236. [CrossRef]

30. Carter, C.R.; Rogers, D.S. A framework of sustainable supply chain management: Moving toward new theory. Int. J. Phys. Distr. Log. 2008, 38, 360-387. [CrossRef]

31. Tate, W.L.; Ellram, L.M.; Kirchoff, F. Corporate social responsibility reports: A thematic analysis related to supply chain management. J. Supply. Chain. Manag. 2010, 46, 19-44. [CrossRef]

32. Boehe, D.M.; Cruz, L. Corporate social responsibility, product differentiation strategy and export performance. J. Bus. Ethics. 2010, 91, 325-346. [CrossRef]

33. Hoejmose, S.; Brammer, S.; Millington, A. An empirical examination of the relationship between business strategy and socially responsible supply chain management. Int. J. Oper. Prod. Man. 2013, 33, 589-621. [CrossRef]

34. Basta, M.; Lapalme, J.; Paquet, M.; Saint-Louis, P.; Abu, Z.T. How are supply chains addressing their social responsibility dilemmas? Review of the last decade and a half. Corp. Soc. Responsib. Environ. Manag. 2018, 25, 833-843. [CrossRef]

35. Guo, R.; Lee, H.L.; Swinney, R. Responsible sourcing in supply chains. Manag. Sci. 2016, 62, $2722-2744$. [CrossRef]

36. Plambeck, E.L.; Taylor, T.A. Supplier evasion of a buyer's audit: implications for motivating supplier social and environmental responsibility. MESom-Manut. Serv. Op. 2016, 18, 184-197.

37. Chen, J.; Hu, Q.; Song, J.S. Supply chain models with mutual commitments and implications for social responsibility. Prod. Oper. Manag. 2017, 26, 268-1283. [CrossRef]

38. Wu, Y.; Li, H.; Gou, Q.; Gu, J. Supply chain models with corporate social responsibility. Int. J. Prod. Res. 2017, 55, 6732-6759. [CrossRef]

39. Ma, P.; Shang, J.; Wang, H. Enhancing corporate social responsibility: Contract design under information asymmetry. Omega-Int. J. Manag. S. 2017, 67, 19-30. [CrossRef]

40. Kraft, T.; Valdés, L.; Zheng, Y. Supply chain visibility and social responsibility: Investigating consumers' behaviors and motives. MESom-Manut. Serv. Op. 2018, 20, 601-800.

41. Yang, D.; Xiao, T.; Huang, J. Dual-channel structure choice of an environmental responsibility supply chain with green investment. J. Clean. Prod. 2019, 210, 134-145. [CrossRef]

42. Ni, D.; Li, K.W.; Tang, X. Social responsibility allocation in two-echelon supply chains: Insights from wholesale price contracts. Eur. J. Oper. Res. 2010, 207, 1269-1279. [CrossRef]

43. Panda, S. Coordination of a socially responsible supply chain using revenue sharing contract. Transp. Res. E-Log. 2014, 67, 92-104. [CrossRef]

44. Hsueh, C.F. Improving corporate social responsibility in a supply chain through a new revenue sharing contract. Int. J. Prod. Econ. 2014, 151, 214-222. [CrossRef]

45. Zhao, X.; Yin, R. Coordination of a socially responsible two-stage supply chain under price-dependent random demand. 4OR 2018, 16, 379-400. [CrossRef]

46. Raza, S.A. Supply chain coordination under a revenue-sharing contract with corporate social responsibility and partial demand information. Int. J. Prod. Econ. 2018, 205, 1-14. [CrossRef]

47. Modak, N.M.; Panda, S.; Sana, S.S. Pricing policy and coordination for a two-layer supply chain of duopolistic retailers and socially responsible manufacturer. Int. J. Logist. Res. Appl. 2015, 19, 487-508. [CrossRef]

48. Panda, S.; Modak, N.M.; Basu, M.; Goyal, S. Channel coordination and profit distribution in a social responsible three-layer supply chain. Int. J. Prod. Econ. 2015, 168, 224-233. [CrossRef]

49. Modak, N.M.; Panda, S.; Mishra, R.; Sana, S. A three-layer supply chain coordination in socially responsible distribution system. Tékhne 2016, 14, 75-87. [CrossRef] 
50. Panda, S.; Modak, N.M. Exploring the effects of social responsibility on coordination and profit division in a supply chain. J. Clean. Prod. 2016, 139, 25-40. [CrossRef]

51. Cachon, G.P.; Lariviere, M.A. Supply chain coordination with revenue-sharing contracts: Strengths and limitations. Manag. Sci. 2005, 51, 30-44. [CrossRef] 